\title{
Does Japan have acid rain?
}

Tokyo

SuDDEN fears that Japan, like Europe and North America, may be suffering from the effects of acid rain have triggered the start of an emergency survey of the forests around Tokyo. The Environment Agency announced the survey last week and preliminary data should be collected by April.

The emergency survey was provoked by two new research reports, from the Gunma Prefectural Health and Pollution Research Centre and Chiba University, that show evidence of extensive damage to trees by air pollution in the Kanto plain (the plain surrounding Tokyo). The news came as a shock; in Japan rainfall is abundant and rivers short so pollutants should be quickly washed away. But what was thought more important is that Japan has some of the world's strictest air pollution legislation.

The legislation was occasioned by some appalling cases of air pollution during Japan's period of rapid industrial growth. In the 1960s, as the Japanese economy

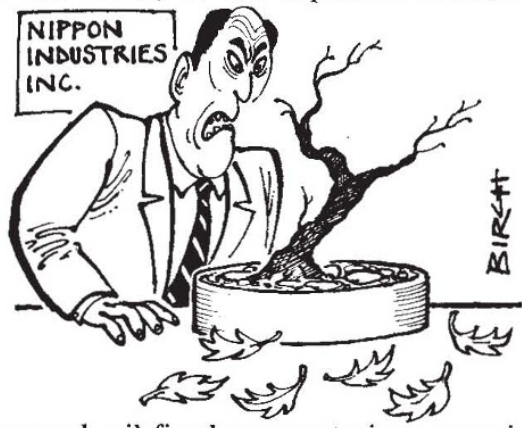

boomed, oil-fired power stations were introduced very rapidly and sulphur oxides were poured into the air. In the refinery town of Yokkaichi, for example, conditions grew so bad that special face masks had to be issued to primary school children. Public protests led to government action: by the end of the 1960 s, measures were under way to desulphurize heavy oil and to reduce the sulphur in emissions from smoke stacks. Then in the 1970s, a fierce battle was fought over another major air pollution source: automobile exhaust emissions. Despite delays, the citizens groups and local governments that took on the giant automobile manufacturers won. Emission standards for carbon monoxide and nitrates were adopted which were the strictest in the world. Petrol has been lead-free for more than 10 years.

Measurements of air pollution seemed to confirm that speedy action had prevented the occurrence of acid rain. Unofficial surveys carried out by volunteer groups and coordinated by scientists from the Environment Agency's research institute suggest that the annual mean $\mathrm{pH}$ of rain in Japan is in the range 4.3-4.4 with a minimum annual average of $p \mathrm{H} \mathrm{4.0.} \mathrm{As}$ unpolluted rain has a $p \mathrm{H}$ around 5 from natural inputs of sulphur oxides (from volcanic eruptions and the like), these levels of acidity seemed no cause for concern. Even during the rainy season from June to July when frequent drizzle favours the production of acid rain, $p \mathrm{H}$ levels did not appear particularly low. A survey of the area around Tokyo Bay carried out in the rainy seasons of $1975-1978$ showed an average $p \mathrm{H}$ of 4.4 for Tokyo, and of 4.0 and 3.8 for the heavy industry areas of Kawasaki and Yokohama, respectively.

Despite these generally optimistic findings, there have been occasions when rainfall has become very acid - around $p \mathrm{H}$ 2.8 - and caused skin and eye irritation, but these were rare events related to unusual weather conditions. Observations of air pollution also remain patchy and insufficient funds are available to complete the analysis and publication of the most up-to-date data collected.

And of course the biggest problem of all is that without clear understanding of the mechanism of formation and effects of acid rain it is very hard to know exactly what should be monitored. Ozone levels, for example, are known to be high in Japan and may be an important factor in forest damage. And although the $p \mathrm{H}$ levels measured around Tokyo are higher than those found experimentally to cause damage to plants, they are not much different from those in areas of Europe affected by "acid rain".

New results described at a small conference held at the National Institute for Environmental Studies at the end of January came as something of a shock. A survey of sugi (the Japanese cedar) carried out by Dr Keiji Takahashi of Chiba University in the Kanto plain revealed much damage that could not be attributed to normal environmental causes, salt-winds, insects, winter winds and the like. Sugi is the most widely planted forest tree in Japan and because it is often grown in shrine precincts there are many old trees available for study. Many trees showed symptoms of "die-back" - loss of leaves on the topmost branches apparently similar to that seen in the dying forests of northern Europe, with old trees most affected. At the end of last year, worrying results were also announced by Dr Kyoichi Sekiguchi of the Health and Pollution Research Institute of Gunma Prefecture, to the northwest, and downwind, from Tokyo. In some parts of the north-western Kanto plain, as many as 80 per cent of cedars seemed to be affected. In Maebashi City, some $100 \mathrm{~km}$ north-east of the main industrial zone surrounding Tokyo Bay, sul- phates and nitrates are transported by wind and in the rainy season produce rain with a $\mathrm{pH}$ around 3.5 .

The new survey will attempt to find out whether a real problem exists. A budget of 8.2 million yen (US $\$ 45,000$ ) has been allocated for study of an area within a hundred kilometres of Tokyo which includes both the Kanto plain and the edges of the mountains that surround it. The Forest Agency's research institute will carry out survey of the cedars while the Environment Agency will look at soil, water and air pollutants. If there is cause for concern then it is likely that larger projects will quickly be launched.

Alun Anderson

The Japan Prize

Tokyo

WinNers of Japan's answer to the Nobel Prize were announced in Tokyo last week. This year Japan Prizes go to Professors Willem J. Kolff (University of Utah) and David Turnbull (Harvard University).

The prize, now in its second year, is worth 50 million yen (more than US\$250,000) and is to be awarded to two people each year. It was set up with funds provided by Kohnosuke Matsushita, head of the giant electronics company that bears his name, and is run by a foundation under the guidance of the Prime Minister's office. Its aims are a little different from the Nobel prize, for it is intended to reward achievements in science and technology that contribute to the peace and prosperity of mankind: thus, appropriately enough for Japan, it has a slightly more appliedscience flavour than the Nobel prize.

Two fields are selected each year. This year, as last, both are fields in which Japanese industrial researchers are active and in which the Ministry of International Trade and Industry is supporting large projects, although, perhaps out of modesty, a Japanese scientist has yet to win the prize. Professor Willem Kolff was chosen for his contributions to "medical technology". Professor Kolff is known as the "father" of artificial organs. He developed an artifical kidney in the Netherlands in 1943; after his move to the United States, he succeeded with an artificial lung and has played a key role in research on artificial hearts. He is now a US citizen.

Professor David Turnbull gained the prize in "material science" for his work on the theory of amorphous materials. In the 1950s he predicted that any liquid, if cooled quickly and if sufficiently viscous, can be transformed to a "glassy" amorphous state. His hypothesis has since been experimentally confirmed and has led to understanding of the structure and properties of numerous glassy metals, alloys, polymers and ceramics. These new materials are finding diverse applications, from solar cells to lightweight but strong structures. Alun Anderson 